Tohoku J. exp. Med., 1976, 119, 1-7

\title{
Effects of Combined Use of Droperidol with Pentazocine and with Fentanyl on Pulmonary Hemodynamics
}

\author{
Kotaro Takahashi, Mrchio Yoshinari, Toshi Arai and \\ KenICHI IwatsukI \\ Department of Anesthesiology, Tohoku University School of \\ Medicine, Sendai
}

\begin{abstract}
Takahashi, K., Yoshinart, M., Arai, T. and Iwatsuki, K. Effects of Combined Use of Droperidol with Pentazocine and with Fentanyl on Pulmonary Hemodynamics. Tohoku J. exp. Med., 1976, 119 (1), 1-7 — The effects of droperidol combined with pentazocine and with fentanyl on the pulmonary hemodynamics were investigated in intact dogs anesthetized with urethanechloralose, and the results were compared with those of each analgesic alone. Mean pulmonary arterial pressure and pulmonary driving pressure remained almost unchanged after droperidol and pentazocine. Pulmonary vascular resistance decreased significantly, and pulmonary vascular compliance and its radius tended to increase. These results indicate that droperidol counteracts the vasoconstrictive action of pentazocine on the pulmonary hemodynamics. On the contrary, almost; all the parameters of the pulmonary hemodynamics after droperidol and fentanyl changed to similar directions to those after fentanyl alone. Droperidol seemed not to modify but to exaggerate the pulmonary circulatory effects of fentanyl. pulmonary hemodynamics; droperidol; pentazocine; fentanyl
\end{abstract}

Previously we reported that pentazocine produced pulmonary hypertension due to its direct vasoconstriction in anesthetized dogs, while fentanyl lowered pulmonary arterial pressure (Takahashi and Iwatsuki 1974). In clinical anesthesia, these analgesics are often used in combination with droperidol as neuroleptanesthesia (Iwatsuki et al. 1971). Therefore, the present study was undertaken to investigate the pulmonary circulatory effects of droperidol combined with pentazocine and with fentanyl, and the results were compared with those of each analgesic alone in the previous report.

\section{Materials and Methods}

Fourteen mongrel dogs were anesthetized with ethyl carbamate $(800 \mathrm{mg} / \mathrm{kg}$ ) and chloralose $(60 \mathrm{mg} / \mathrm{kg})$. Following endotracheal intubation, respiration was controlled with pure oxygen using a volume-preset respirator (AIKA R-50). End-tidal $\mathrm{CO}_{2}$ content was maintained at approximately $5 \%$ with the Beckman medical gas analyzer.

Mean arterial pressure, mean pulmonary arterial pressure (MPAP) and mean left atrial pressure (MLAP) were measured by electric manometers (Nihon Kohden MP-3A), and they were recorded on a polygraph. Heart rate was read from the recorder. Cardiac

Received for publication, December 8, 1975. 
output was determined by the dye dilution method using a dye densitometer (Erma Optical Works Model EN-6) and a blood flow computer (Erma Optical Works Model EW-90). Mean pulmonary transit time (MPTT) was also determined by the dye indication method.

Stroke volume, total peripheral vascular resistance (TPVR), mean pulmonary arterial driving pressure (MPADP), mean pulmonary intravascular pressure (MPIVP), pulmonary vascular resistance (PVR), the ratio of PVR to TPVR (Rp/Rs), pulmonary blood volume (PVB), and pulmonary vascular compliance (PVC) were calculated. Pulmonary vascular tension (T) and radius ( $r$ ) were also calculated after Linde et al. (1972). The details of the method are shown in the previous paper (Takahashi and Iwatsuki 1974).

Droperidol $0.3 \mathrm{mg} / \mathrm{kg}$ was administered intravenously together with pentazocine $2.0 \mathrm{mg} / \mathrm{kg}$ or with fentanyl $0.01 \mathrm{mg} / \mathrm{kg}$ in each group of $7 \mathrm{dogs}$. The measurements were carried out before, and $15 \mathrm{~min}$ and $30 \mathrm{~min}$ after administration of these drugs.

\section{Results}

The results obtained from the combined administration of droperidol and pentazocine are summarized in Table 1 and are illustrated in Figs. 1 and 2 in comparison with those obtained from pentazocine alone.

Mean pulmonary arterial pressure, mean pulmonary arterial driving pressure and mean pulmonary intravascular pressure remained almost unchanged after droperidol and pentazocine. On the contrary, a significant elevation was seen in them after the same dose of pentazocine alone. The differences between the corresponding values in each group were highly significant. Mean left atrial pressure tended to decrease in both groups. A decrease in pulmonary vascular resistance and an increasing tendency in pulmonary vascular compliance were seen after droperidol and pentazocine, and vice versa after pentazocine alone. Pulmonary vascular radius tended to increase after droperidol and pentazocine, while it decreased after pentazocine alone, with a significant difference between the

TABLE 1. Effects of droperidol and pentazocine on systemic and pulmonary hemodynamics

\begin{tabular}{|c|c|c|c|}
\hline & Control & $15 \min$ & $30 \mathrm{~min}$ \\
\hline Mean arterial pressure (mmHg) & $138.6 \pm 30.0$ & $105.0 \pm 25.7 \uparrow$ & $104.3 \pm 29.3 \dagger$ \\
\hline Heart rate (beats/min) & $152.6 \pm 39.6$ & $164.6 \pm 35.8$ & $168.0 \pm 38.6$ \\
\hline Cardiac output (liter/min) & $1.30 \pm 0.53$ & $1.48 \pm 0.56$ & $1.43 \pm 0.43$ \\
\hline Stroke volume (ml) & $8.5 \pm 2.3$ & $9.0 \pm 2.4$ & $8.6 \pm 1.8$ \\
\hline Total peripheral vascular resistance $\left(\right.$ dyne $\left.\cdot \mathrm{sec} \cdot \mathrm{cm}^{-5}\right)$ & $9057 \pm 1776$ & $5871 \pm 929$ & $5900 \pm 1200 \dagger$ \\
\hline Mean pulmonary arterial pressure $(\mathrm{mmHg})$ & $18.3 \pm 6.5$ & $18.0 \pm 6.0^{\dagger}$ & $16.3 \pm 4.9$ \\
\hline Mean left atrial pressure $(\mathrm{mmHg})$ & $2.9 \pm 2.1$ & $1.9 \pm 1.4$ & $1.6 \pm 1.4^{*}$ \\
\hline Mean pulmonary arterial driving pressure $(\mathrm{mmHg})$ & $14.6 \pm 4.9$ & $15.1 \pm 5.2$ & $14.7 \pm 4.5$ \\
\hline Mean pulmonary intravascular pressure ( $\mathrm{mmHg}$ ) & $10.1 \pm 4.2$ & $9.4 \pm 3.3$ & $8.9 \pm 2.8$ \\
\hline Pulmonary vascular resistance $\left(\right.$ dyne $\left.\cdot \mathrm{sec} \cdot \mathrm{cm}^{-5}\right)$ & $958 \pm 340$ & $890 \pm 374^{*}$ & $850 \pm 340$ \\
\hline $\mathrm{Rp} / \operatorname{Rs}(\%)$ & $10.7 \pm 3.4$ & $15.4 \pm 6.2 \dagger$ & $15.2 \pm 5.9 \dagger$ \\
\hline Mean pulmonary transit time (sec) & $3.18 \pm 0.90$ & $2.75 \pm 0.74^{*}$ & $2.89 \pm 1.00$ \\
\hline Pulmonary blood volume (ml) & $65.2 \pm 19.9$ & $65.0 \pm 20.4$ & $65.2 \pm 22.2$ \\
\hline Pulmonary vaseular compliance $(\mathrm{ml} / \mathrm{mmHg})$ & $7.19 \pm 2.51$ & $7.37 \pm 2.31$ & $7.79 \pm 2.65$ \\
\hline Pulmonary vascular radius & & $1.03 \pm 0.03$ & $1.03 \pm 0.04$ \\
\hline Pulmonary vascular tension & & $0.99 \pm 0.13$ & $0.95 \pm 0.16$ \\
\hline
\end{tabular}

Meants.D. ${ }^{*} p<0.05, \quad \dagger p<0.01$. 


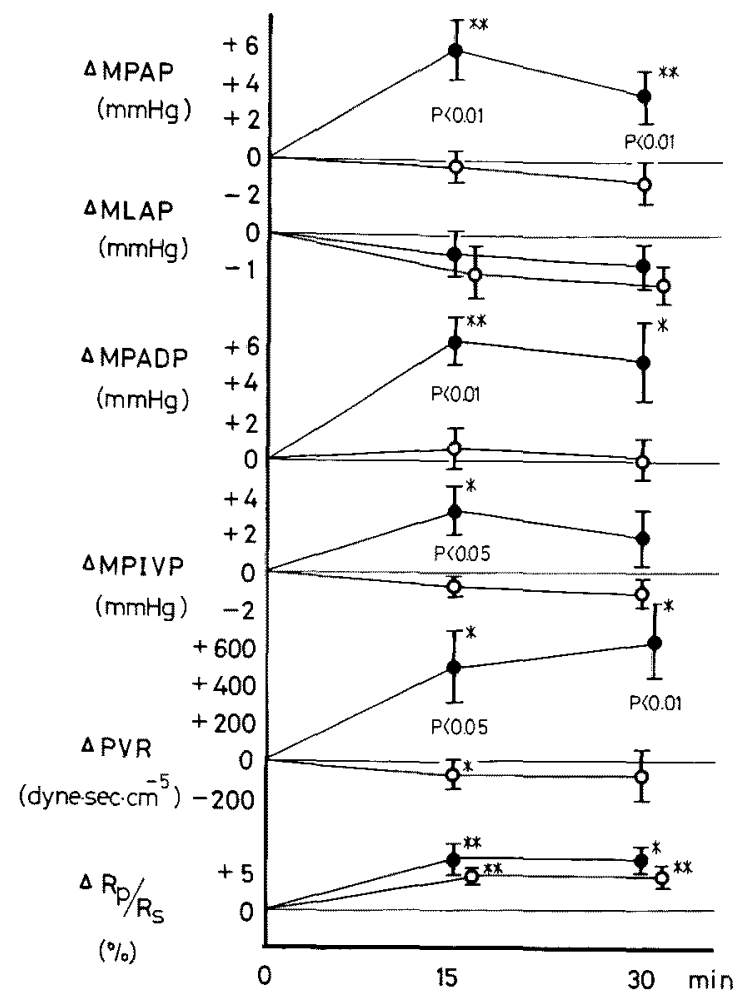

Fig. 1. Effects of pentazocine alone and those of droperidol and pentazocine on MPAP, MLAP, MPADP, MPIVP, PVR and Rp/Rs. Vertical bars are \pm s.E., and star marks indicate significant changes to each control value $(* p<0.05, * * p<0.01) . p$ values in the figure represent significant differences between the corresponding data in each group. See abbreviations in the text. $\bullet, \mathrm{P} ; \mathrm{o}, \mathrm{P}+\mathrm{D}$.

TABLE 2. Effects of droperidol and fentanyl on systemic and pulmonary hemodynamics

\begin{tabular}{|c|c|c|c|}
\hline & Control & $15 \mathrm{~min}$ & $30 \min$ \\
\hline Mean arterial pressure $(\mathrm{mmHg})$ & $130.7 \pm 26.2$ & $93.6 \pm 16.8 \dagger$ & $91.4 \pm 18.4 \dagger$ \\
\hline Heart rate (beats/min) & I $37.1 \pm 9.4$ & $132.0 \pm 36.7^{*}$ & $140.6 \pm 27.5$ \\
\hline Cardiac output (liter $/ \mathrm{min}$ ) & $1.59 \pm 0.48$ & $1.24 \pm 0.41^{*}$ & $1.07 \pm 0.25 \dagger$ \\
\hline Stroke volume $(\mathrm{ml})$ & $11.5 \pm 3.1$ & $9.5 \pm 1.9 \dagger$ & $7.9 \pm 2.2^{*}$ \\
\hline Total peripheral vascular resistance $\left(\right.$ dyne $\cdot \mathrm{sec} \cdot \mathrm{cm}^{-5}$ ) & $6870 \pm 1473$ & $6364 \pm 1762$ & $7100 \pm 2135$ \\
\hline Mean pulmonary arterial pressure (mmHg) & $17.1 \pm 4.2$ & $13.8 \pm 2.6^{*}$ & $13.1 \pm 1.3^{*}$ \\
\hline Mean left atrial pressure $(\mathrm{mmHg})$ & $1.3 \pm 1.9$ & $-0.4 \pm 1.7^{*}$ & $-0.8 \pm 1.8 \dagger$ \\
\hline Mean pulmonary arterial driving pressure (mmHg) & $15.9 \pm 3.7$ & $141.1 \pm 3.5$ & $13.9 \pm 2.5$ \\
\hline Mean pulmonary intravascular pressure $(\mathrm{mmHg})$ & $9.2 \pm 2.7$ & $6.6 \pm 1.2 \dagger$ & $6.1 \pm 0.9 \dagger$ \\
\hline Pulmonary vascular resistance $\left(\right.$ dyne $\left.\cdot \mathrm{sec} \cdot \mathrm{cm}^{-6}\right)$ & $838 \pm 242$ & $953 \pm 246^{*}$ & $1093 \pm 330^{*}$ \\
\hline $\operatorname{Rp} / \operatorname{Rs}(\%)$ & $12.4 \pm 3.5$ & $15.7 \pm 5.7 \dagger$ & $16.1 \pm 6.3^{*}$ \\
\hline Mean pulmonary transit time (sec) & $2.61 \pm 0.52$ & $3.18 \pm 0.53 \dagger$ & $3.46 \pm 0.63 \dagger$ \\
\hline Pulmonary blood volume (ml) & $66.7 \pm 15.4$ & $63.0 \pm 11.8$ & $60.6 \pm 11.0$ \\
\hline Pulmonary vascular compliance $(\mathrm{ml} / \mathrm{mmHg})$ & $7.45 \pm 1.87$ & $9.60 \pm 2.14 \dagger$ & $10.0 \pm 1.93 \dagger$ \\
\hline Pulmonary vascular radius & & $0.97 \pm 0.03^{*}$ & $0.94 \mp 0.05^{*}$ \\
\hline Pulmonary vascular tension & & $0.74 \pm 0.10 \dagger$ & $0.65 \pm 0.12 \dagger$ \\
\hline
\end{tabular}

Meants.D. $* p<0.05, \quad+p<0.01$. 


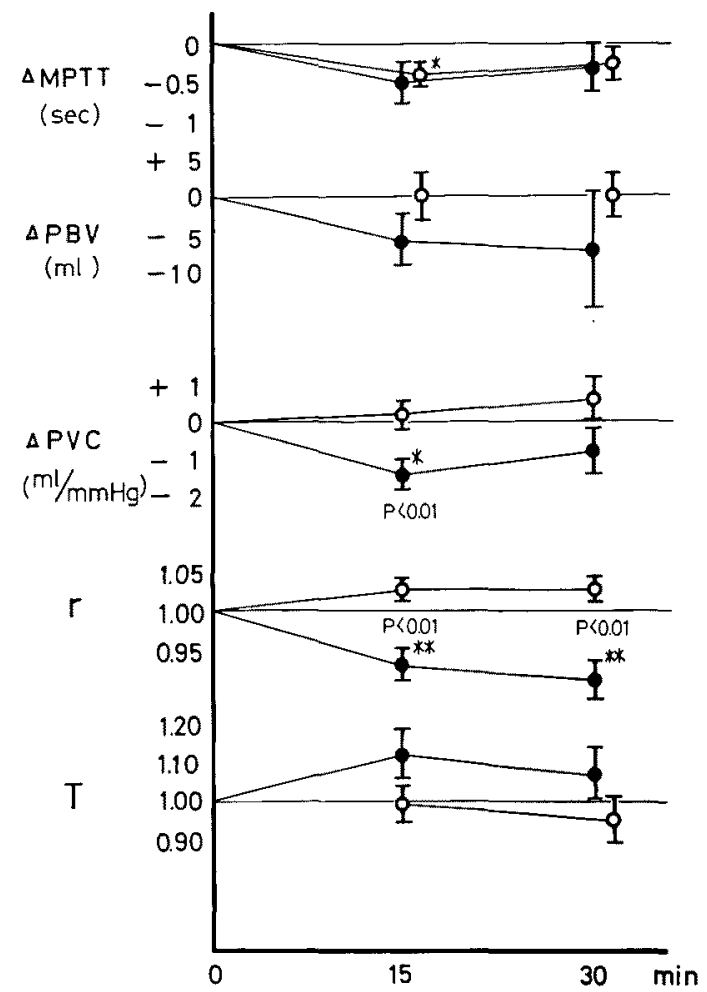

Fig. 2. Effects of pentazocine alone and those of droperidol and pentazocine on MPTT, PBV, PVC, pulmonary vascular radius $(r)$ and tension $(\mathrm{T})$. Vertical bars are \pm s.E., and star marks indicate significant changes to each control value $\left({ }^{*} p<0.05,{ }^{* *} p<0.01\right) . \quad p$ values in the figure represent significant differences between the corresponding data in each group. See abbreviations in the text. $\bullet, P ; O, P+D$.

values in each group. Pulmonary vascular tension was not so much altered after droperidol and pentazocine. An increase in $\mathrm{Rp} / \mathrm{Rs}$ and a shortening in mean pulmonary transit time were seen in both groups.

The results obtained from the combined administration of droperidol and fentanyl are summarized in Table 2 and are illustrated in Figs. 3 and 4 in comparison with those obtained from fentanyl alone.

Mean arterial pressure, cardiac output and stroke volume were decreased significantly, but heart rate and total peripheral vascular resistance were almost unchanged.

Mean pulmonary arterial pressure, mean left atrial pressure and mean pulmonary intravascular pressure were significantly lowered after droperidol and fentanyl. Mean pulmonary arterial driving pressure also tended to decrease. In spite of a pressure decrease in the pulmonary vasculature, pulmonary vascular resistance and $\mathrm{Rp} / \mathrm{Rs}$ were increased significantly. There was a significant prolongation in mean pulmonary transit time, but pulmonary blood volume was 


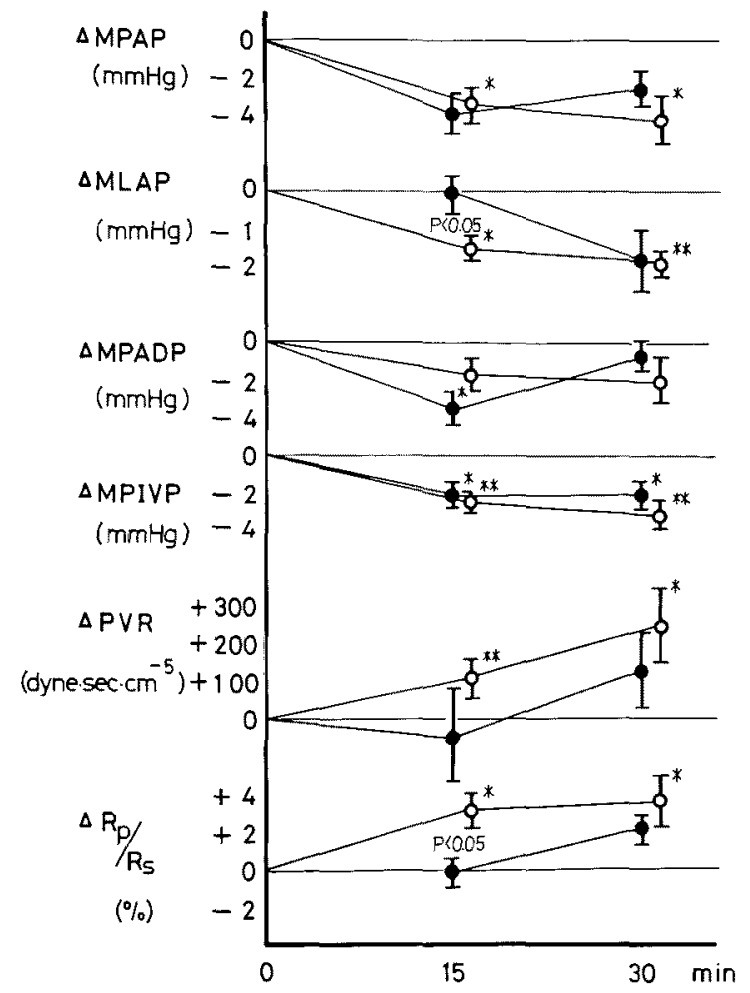

Fig. 3. Effects of fentanyl alone and those of droperidol and fentanyl on MPAP, MLAP, MPADP, MPIVP, PVR and Rp/Rs. Vertical bars are \pm s.e., and star marks indicate significant changes to each control value $\left({ }^{*} p<0.05,{ }^{* *} p<0.01\right) . \quad p$ values in the figure represent significant differences between the corresponding data in each group.

$\bullet \mathrm{F} ; \mathrm{O}, \mathrm{F}+\mathrm{D}$.

slightly decreased. Pulmonary vascular compliance was increased, but its tension and radius were decreased significantly.

Almost all the parameters after droperidol and fentanyl changed to similar directions to those after fentanyl alone. Left atrial pressure and $\mathrm{Rp} / \mathrm{Rs}$, however, showed a significant difference between the two groups.

\section{Discússion}

We reported previously that pentazocine exerted a direct vasoconstrictive action on the pulmonary vasculature. The present study indicates that the vasoconstrictive action of pentazocine is counteracted by droperidol when they are used together. A significant decrease in pulmonary vascular resistance, which is concomitant with little change in mean pulmonary arterial pressure and pulmonary driving pressure, suggests that droperidol and pentazocine may produce a slight pulmonary vasodilatation. This is also supported by an increasing tendency in pulmonary vascular compliance and radius. A significant rise in $R p / R$ s after 


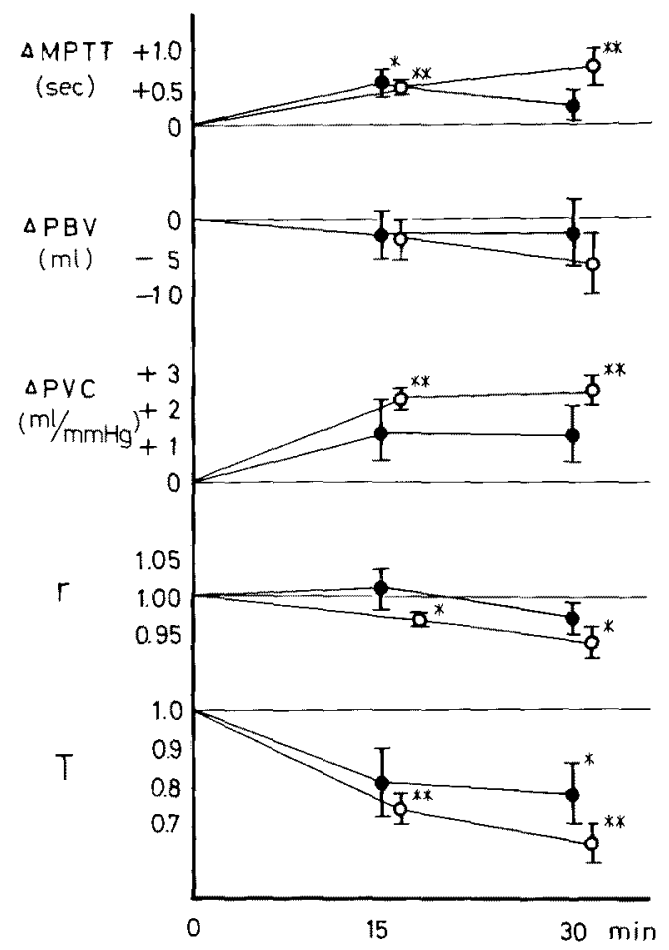

Fig. 4. Effects of fentanyl alone and those of droperidol and fentanyl on MPTT, PBV, PVC, pulmonary vascular radius $(r)$ and tension $(\mathrm{T})$. Vertical bars are \pm s.E., and star marks indicate significant changes to each control value $\left({ }^{*} p<0.05,{ }^{*} p<0.01\right)$. $\bullet$ F; $0, F+D$.

droperidol and pentazocine indicates that the systemic peripheral vaseular beds are affected more by these drugs than the pulmonary vasculature.

Pentazocine has been reported to increase plasma catecholamine levels (Tammisto et al. 1971). On the othe hand, droperidol has been postulated to possess a potent alpha-adrenergic blocking action (Yelnofsky et al, 1964), and the alpha-adrenergic mechanism plays a predominant role in the pulmonary circulation as compared with the beta-adrenergic mechanism (Porcelli and Bergofsky 1973). Consequently, when these agents are used together, the pulmonary vasoconstrictive action of pentazocine is thought to be abolished by droperidol.

In the previous paper, fentanyl was shown to reduce pulmonary arterial pressure, not owing to its direct effects on the pulmonary vasculature, but owing to a decrease in pulmonary blood flow resulted from systemic cardiovascular depression. All the changes in the pulmonary hemodynamics seen after droperidol and fentanyl are thought also to be attributed to a decrease in pulmonary blood flow.

Pulmonary vascular resistance was increased significantly after droperidol and fentanyl, although mean pulmonary arterial pressure and mean pulmonary intravascular pressure were decreased significantly. As Rudolph and Auld (1960) 
pointed out, a decrease in pulmonary blood flow might mislead to high pulmonary vascular resistance without any change in pulmonary vascular tone. High pulmonary vascular resistance observed after droperidol and fentanyl seems to correspond to such a situation.

In spite of a decrease in pulmonary vascular tension and an increase in pulmonary vascular compliance, pulmonary vascular radius which corresponded to cross-sectional area of the functioning pulmonary vasculature decreased significantly after droperidol and fentanyl. Therefore, the pulmonary circulatory effects after droperidol and fentanyl seem not due to pulmonary vasodilatation, but due to a decrease in pulmonary blood flow. These results indicate that droperidol does not modify, but exaggerates the pulmonary circulatory effects of fentanyl.

\section{References}

1) Iwatsuki, K., Suzuki, M., Yusa, T. \& Hashimoto, Y. (1971) Modified neuroleptanesthesia using droperidol and pentazocine. Tohoku J. exp. Med., 104, 111-120.

2) Linde, L.M., Goldberg, S.J., Momma, K., Awa, S. \& Hall, V.E. (1972) Pulmonary vascular pressure response as a function of blood flow. Cardiovasc. Res., 6, 415-422.

3) Porcelli, R.J. \& Bergofsky, E.H. (1973) Adrenergic receptors in pulmonary vasoconstrictor responses to gaseous and humoral agents. J. appl. Physiol., 34, $483-488$.

4) Rudolph, A.M. \& Auld, P.A.M. (1960) Physical factors affecting normal and serotoninconstricted pulmonary vessels. Amer. J. Physiol., 198, 864-872.

5) Tammisto, T., Jäättelä, A., Nikki, P. \& Takki, S. (1971) Effect of pentazocine and pethidine on plasma catecholamine levels. Ann. cli. Res., 3, 22-29.

6) Takahashi, K. \& Iwatsuki, K. (1974) Effects of pentazocine and fentanyl on the pulmonary hemodynamics. Tohoku $J$. exp. Med., 113, 89-95.

7) Yelnofsky, J, Kats, R. \& Dietrich, E.V. (1964) A study of some of the pharmacologic action of droperidol. Toxicol. appl. Pharmacol., 6, 37-47. 